For this issue, Bois et Forêts des Tropiques opened its editorial page of the expression of opinion ${ }^{1}$.

\section{Are logging concessions a threat to the peatlands in DRC?}

Sylvie Gourlet-Fleury et al.

In a letter jointly signed by 30 researchers and addressed publically to the Norwegian Ministry of Climate and Environment, Professor Simon Lewis (University of Leeds) and his colleagues denounced the potentially negative impact of logging in the vast swamplands of the Congolese Cuvette, which partly comprises peatlands. The letter requested that Norway refuse to fund a programme for sustainable forest management in the Democratic Republic of Congo (DRC) submitted by Agence Française de Développement (AFD) in 2017. The purpose of this programme is to revive legal logging, which is in sharp decline in the country, and to back better management of forest resources by providing support to the national and provincial forestry boards, and by improving governance.

In DRC, as in the Republic of Congo, the law authorizes the inclusion of these swamplands in the concessions granted to logging companies. While quite rare in the Republic of Congo, in DRC around 4.5 million hectares, i.e. $26 \%$ of the swamplands in the country, are entirely or partially covered by thirty or so concessions.

The main criticism made against AFD is that it has not considered the potential damage that logging in these concessions could cause in the peatlands. That criticism was justified by explicitly referring to the damage caused by this type of operation in the peatlands of Indonesia.

As scientists, we recognize the quality of the work done by Pr. Lewis and his colleagues and we are aware of the need to protect the peatlands of the Congolese Cuvette. However, we do question, in both substance and form, the arguments put forward by the team of researchers in its letter on how to achieve it.

\section{Protecting peatlands makes sense in a context of climate change}

The Congo Basin is home to one of the vastest wetlands on the planet. These permanently or periodically waterlogged swamplands, largely covered by forests, extend over around 26 million hectares, mapped in 2014 by Betbeder and colleagues. A paper published in the journal Nature (Dargie et al., 2017) recently confirmed the existence of peatlands under 14.5 million hectares, estimated to be permanently waterlogged.

It is recognized by all that peatlands store a very large amount of carbon in their soil. Damage to peatlands under the combined effect of deforestation and drainage leads

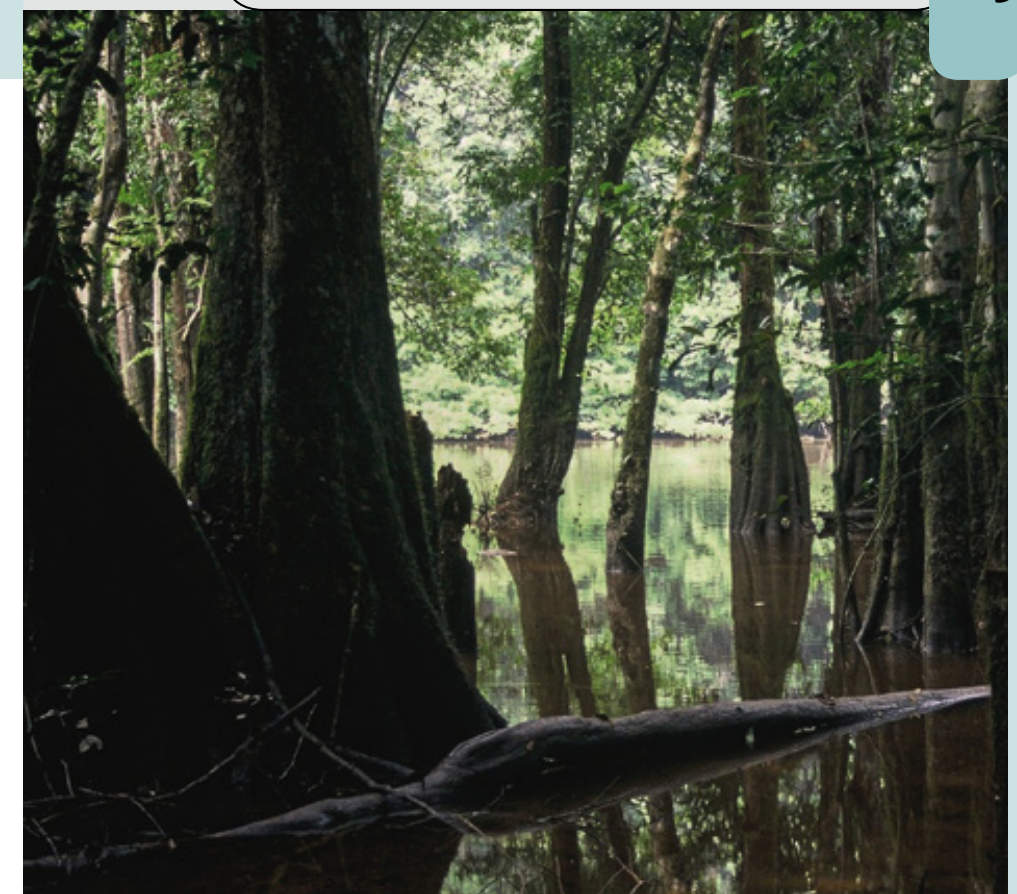

Forêt marécageuse, parc national de l'Ivindo (Gabon). Swamp forest, Ivindo National Park (Gabon).

Photo C. Doumenge.

to massive $\mathrm{CO}_{2}$ emissions into the atmosphere; most of this gas comes from the decomposition of the peat in the drained zone above the water table. This drying out of peatlands, notably in a context of climate change causing periods of drought that are more intense during $\mathrm{El} \mathrm{Niño}$ events, also considerably increases the risk of fire, another factor in $\mathrm{CO}_{2}$ emissions. Avoiding activities that might entail a risk of drying out these peatlands is therefore strategic.

\section{Logging may be a risk for peatlands}

The risk involved in legal logging in the forests covering part of the swamplands is not the actual removal of the trees (involving one tree/ha on average), but the opening up of access tracks. The track network may encroach upon the swamplands: they have to be crossed to gain access to the loggable areas on stable ground. Crossing swamplands necessitates a clearing in the forest, and involve the compaction of the peat requiring the addition of large quantities of soil and sand and a disruption of the natural water drainage network. In addition, when access to the tracks is not effectively controlled, other activities may develop inside the concessions, such as slash and burn agriculture and illegal timber logging, increasing the risk of degradation.

Loggers not respecting the law heighten that risk. In particular, some sought-after valuable species growing in periodically waterlogged areas are logged, and the annual logging authorizations fixing a maximum volume of wood to be removed are not always heeded.

However, the hypothesis whereby the drying out of peatlands could be brought about in DRC by logging in the forest concessions, as has occurred in Indonesia, is unlikely given the context in that country. 


\section{However, the situation in DRC is not the same as in Indonesia}

In Indonesia, the main cause of peatland degradation is the conversion to farmland and the creation of large-scale plantations for the paper industry, sometimes after logging of the natural forests. Such conversions, which were encouraged by the State as part of its agricultural colonization policy, required substantial drainage and water management work to make the zones usable for the human populations. There have been numerous failures and the ecological disaster is obvious in many places. Logging itself has rarely needed peatland drainage, except near rivers and in certain coastal areas where canals have been constructed to take out logs.

In DRC, the swamplands of the Congolese Cuvette are not earmarked for an agricultural colonization plan, especially for cash crops grown on an industrial scale, and they have no spontaneous forest/agriculture transition zone. Indeed DRC (like the Republic of Congo) still has substantial land reserves on soils that are much more suitable for farming.

Logging in the forest concessions has to be carried out in compliance with management plans that have already been validated to date in around ten of them by the Congolese State. Even though these plans are sometimes insufficiently followed, they seek to guarantee that there is limited impact on the forest and that swamplands are respected. In compliance with a legal obligation found in most of the forestry codes of central Africa, swamplands are incorporated into a protected area of the concession called the "protection series". This is the case in DRC, in a regulatory text in force since 2007 which is currently being reviewed.

Even though the situations clearly differ between these two countries, logging in concessions largely covered by swamplands, which is still rarely the case today, is an operation with risks and it is strictly necessary to respect the management rules.

\section{We believe that directly speaking with the Central African Forest Initiative (CAFI) is a more constructive approach}

The Central African Forest Initiative (CAFI) is a unique collaborative partnership established between several countries and donor organizations including Norway, which currently holds the presidency. The purpose of this partnership is to decide upon and coordinate the attribution of resources from a trust fund (CAFI fund) supporting actions that limit deforestation and forest degradation. Speaking with the secretariat of CAFI would have been more appropriate than speaking with the Norwegian Ministry of Climate and Environment, without referring to CAFI.

Moreover, these organizations have neither the power nor the legitimacy to decide forest management or protection policies in central Africa. Such policies are, above all, the prerogative of the African States themselves. In this respect, the Congolese State already showed that the swamplands were one of its environmental priorities when it defined management and exploitation standards guaranteeing that they are respected. An "Independent
Observer", a Congolese institution tasked with helping to apply the laws and principles of good governance in forestry activities, has been appointed. Lastly, according to the article by Dargie and co-authors (2017), a "Peatland Management Unit" has recently been set up designed to more effectively define peatland zones and control their use.

All these actions need to be taken into account, encouraged and assisted in projects financed by the CAFI fund. As part of its activities, the AFD project should integrate strict a priori and a posteriori impact studies in already managed forest concessions covering swamplands. These studies should particularly focus on how the track network linking terra firma forests affects the functioning of these swamplands. The project should also launch an in-depth consultation, based on impact studies and scientific advice, so that an informed decision can be taken for DRC's forest land use plan. It will be the task of this plan to determine which areas of the Congo Basin in this country must be preserved from any forest logging, development of agribusiness, or extraction activities. Foresight analyses will have to be carried out to evaluate the long-term efficiency of the various alternatives that are available to the government and the Congolese populations to preserve these swamplands and limit climate change.

Scientific evidence is lacking in this region of the world, particularly in the Congolese Cuvette. The nature of the peatlands, their location, the natural and anthropogenic dynamics, and the standards and actions helping to limit human impacts there remain largely unknown. The scientific world wishes to enhance that knowledge and help the Congolese State to more effectively manage its forest resource with a view to sustainably developing and preserving these ecosystems. Blocking projects, such as the one proposed by AFD, rather than entering into discussions with the people who are proposing them, amounts to depriving regional stakeholders of the support they need to choose and control what becomes of these ecosystems of local and global importance.

We agree with the need to protect peatlands and swamplands in general from any economic activity that would lead to ecological damage likely to contribute to climate change. However, we feel it is above all our role, as scientists, to enlighten and assist collaboration between States, local and wider communities, donors, NGOs and logging companies to provide guidance for concerted territorial management.

\section{Références / References}

Betbeder J., Gond V., Frappart F., et al., 2014. Mapping of Central Africa Forested Wetlands Using Remote Sensing. IEEE Journal of Selected Topics in Applied Earth Observations and Remote Sensing, 7 (2): 531-542.

Dargie G. C., Lewis S. L., Lawson I. T., et al., 2017. Age, extent and carbon storage of the central Congo Basin peatland complex. Nature, 542 (7639): 86-90. 